\title{
Insiden Malaria di Puskesmas Sungai Durian dan Puskesmas Talawi Kota Sawahlunto Bulan Oktober 2011 sampai Februari 2012
}

\author{
Mareza Dwithania ${ }^{1}$, Nuzulia Irawati ${ }^{2}$, Rosfita Rasyid ${ }^{3}$
}

\begin{abstract}
Abstrak
Malaria masih merupakan masalah kesehatan dunia, termasuk Indonesia karena angka kesakitan dan kematian akibat penyakit ini cukup tinggi. Tingginya insiden malaria pada suatu daerah dapat dipengaruhi oleh parasit, hospes, dan vektor. Sawahlunto sebagai suatu daerah perbukitan memiliki risiko tinggi untuk penyebaran dan penularan penyakit malaria. Tujuan penelitian ini adalah untuk mengetahui insiden dan distribusi malaria menurut spesies parasit penyebab malaria, derajat infeksi berdasarkan hitung parasit, umur, dan jenis kelamin penderita. Penelitian ini dilakukan terhadap pasien dengan gejala klinis malaria yang berobat ke Puskesmas Sungai Durian dan Puskesmas Talawi dari Oktober 2011 sampai Februari 2012. Data diperoleh dengan pemeriksaan secara mikroskopik sediaan darah tebal dan sediaan darah tipis dari sampel darah tepi yang telah dipulas dengan pewarnaan Giemsa. Hasil penelitian dari 312 sampel terdapat 13 sediaan darah positif malaria. Parasit penyebab malaria yang ditemukan adalah Plasmodium vivax (76,92\%), Plasmodium falciparum (15,38\%) dan Plasmodium malariae (7,69\%). Berdasarkan distribusi derajat infeksi (hitung parasit), semua sampel merupakan infeksi ringan (100\%) dan frekuensi tertinggi ditemukan pada umur $\geq 15$ tahun $(61,54 \%)$ dan jenis kelamin laki-laki $(53,85 \%)$. Insiden malaria di Puskesmas Sungai Durian dan Puskesmas Talawi dominan disebabkan Plasmodium vivax, semua kasus tergolong infeksi ringan, sedangkan distribusi penderita terbanyak pada umur $\geq 15$ tahun dan jenis kelamin laki-laki. Penelitian ini
\end{abstract} menunjukkan penurunan kasus dari tahun sebelumnya.

Kata kunci: Plasmodium, Anopheles, malaria

\begin{abstract}
Malaria is still a global health problem, including in Indonesia due to its high morbidity and mortality. The high incidence of malaria in an area can be influenced by the parasites, hospes, and vectors. Sawahlunto as an area that is surrounded with many hills has a high risk for the spreading and transmission of malaria. The purpose of this study is to determine the incidence and distribution by species of malaria parasite that causes malaria, the degree of infection by the parasite count in positive malaria preparations, age, and sex of the patients. The research was done to the patients who came to the Sungai Durian and Talawi Public Health Center in October 2011 to February 2012. The data was obtained by microscopic examination of thick and thin blood preparations from peripheral blood samples that had been daubed with Giemsa staining. From 312 samples, there were 13 positive malaria blood preparations. This study found the parasites that caused malaria are P.vivax (76.92\%), P.falciparum (15.38\%) and P.malariae (7.69\%). Based on the distribution of parasite count, age and sex of patients, all of the samples are a mild infections (100\%) and the highest frequency was found at age the $\geq 15$ years old (61.54\%) and in male (53.85\%). Most of incidence of malaria at Sungai Durian and Talawi Public Health Center in October 2011 to February 2012 were caused by P.vivax, all cases were classified as mild infection degrees, the highest frequency of malaria parasite was found at age $\geq 15$ years old and according to the sex, most found in male. This study showed decrease cases from the previous year.
\end{abstract}

Keywords: Plasmodium, Anopheles, malaria

Affiliasi penulis: ${ }^{1}$ Mahasiswi FK Unand, ${ }^{2}$ Bagian Parasitologi FK Unand, ${ }^{3}$ Bagian Fisika FK Unand Padang.

Korespondensi: Fakultas Kedokteran Universitas Andalas Jl. Perintis Kemerdekaan No.94, Padang. Email: marezadwithania@yahoo.com.

\section{Pendahuluan}

Malaria adalah penyakit yang disebabkan oleh parasit dari genus Plasmodium dan ditularkan ke manusia melalui gigitan nyamuk Anopheles. ${ }^{1}$ Penyakit ini masih merupakan infeksi parasitik paling penting di dunia, diperkirakan terdapat lebih dari 500 juta kasus malaria pertahun dengan 3 juta kematian.2 Angka kesakitan dan angka kematian di Indonesia masih tinggi terutama di daerah luar Jawa dan Bali, dimana terdapat campuran penduduk dari daerah endemis dan tidak endemis malaria. ${ }^{3,4}$ Kematian karena malaria terutama disebabkan oleh infeksi Plasmodium falciparum dengan berbagai komplikasinya, terutama pada anak-anak, wanita hamil, dan individu non-imun. Malaria sering disalahtafsirkan sebagai penyakit lain sehingga pengobatan yang tepat sering terlambat Diagnosis dini sangat diperlukan untuk mengurangi angka kesakitan dan angka kematian akibat malaria. ${ }^{4,5}$

Di Propinsi Sumatera Barat angka malaria masih cukup tinggi, walaupun sarana kesehatan yang ada sudah meningkat. ${ }^{6}$ Angka Klinis Malaria di Sumatera Barat menunjukkan fluktuasi dari tahun ke tahun. Puncak kejadian malaria selama 10 tahun terakhir ini adalah pada tahun 2009 terdapat 1.357 sediaan positif malaria dari 7.207 malaria klinis yang diambil sediaan darahnya sebanyak 4.067 buah. Hal ini perlu disikapi ke depannya agar indikator program malaria berdasarkan API seperti halnya di Jawa dan Bali. $^{7}$

Kota Sawahlunto menduduki peringkat kedua sebagai AMI tertinggi setelah Kabupaten Kepulauan Mentawai. Sejak tahun 2008 kasus malaria di Kota Sawahlunto cukup tinggi dibanding daerah endemis yang biasa dikenal selama ini, seperti Kabupaten Pesisir Selatan dan Kabupaten Pasaman Barat. 
Peningkatan ini beriringan dengan tingginya angka malaria positif di daerah tetangga Kota Sawahlunto, yaitu Kabupaten Sijunjung. ${ }^{7}$ Selama tiga tahun terakhir di Kota Sawahlunto puncak kasus malaria berada pada bulan Februari dan Oktober, diikuti KLB pada tahun 2008 dengan tiga kematian. Pada tahun 2010 kasus malaria di Kota Sawahlunto ditemukan parasit yang terbanyak adalah Plasmodium vivax. Hal ini berbeda dari data sebelumnya yang menunjukkan bahwa infeksi malaria didominasi oleh Plasmodium falciparum. 8

Tujuan penelitian ini untuk mengetahui insiden malaria pada pasien yang berobat ke Puskesmas Sungai Durian dan Puskesmas Talawi Kota Sawahlunto pada bulan Oktober 2011 sampai Februari 2012 dan distribusinya berdasarkan Plasmodium penyebab malaria, derajat infeksi, serta umur dan jenis kelamin penderita.

\section{Metode}

Populasi penelitian ini adalah semua pasien yang datang berobat ke Puskesmas Sungai Durian dan Puskesmas Talawi Kota Sawahlunto selama Oktober 2011 sampai Februari 2012 dengan gejala klinis malaria. Sampel penelitian adalah sediaan darah tebal dan sediaan darah tipis yang diambil dari pasien yang dicurigai malaria dan dibawa ke Laboratorium Parasitologi Fakultas Kedokteran Universitas Andalas untuk pemeriksaan mikroskopik.

Bahan yang dibutuhkan adalah darah tepi dari ujung jari tengah tangan kiri, alkohol $70 \%$, metanol, zat pewarna Giemsa 5\%, aquadest, dan air kran. Alat-alat yang digunakan, yaitu object glass (kaca sediaan), blood lancet, gelas ukur, pipet tetes, rak pewarnaan, mikroskop, kapas, tissue, dan alat-alat tulis untuk pencatatan data.

\section{Hasil Penelitian dan Pembahasan}

Tabel 1. Distribusi insiden malaria berdasarkan spesies Plasmodium di Puskesmas Sungai Durian dan Puskesmas Talawi Kota Sawahlunto selama Bulan Oktober 2011 sampai Februari 2012.

\begin{tabular}{llcccc}
\hline No & $\begin{array}{c}\text { Spesies } \\
\text { Plasmodium }\end{array}$ & $\begin{array}{c}\text { Pusk. } \\
\text { Sungai } \\
\text { Durian }\end{array}$ & $\begin{array}{c}\text { Pusk. } \\
\text { Talawi }\end{array}$ & Jumlah & $\%$ \\
\hline 1. & P. falciparum & 1 & 1 & 2 & 15,38 \\
2. & P. vivax & 8 & 2 & 10 & 76,92 \\
3. & P. malariae & 1 & - & 1 & 7,69 \\
4. & P. ovale & - & - & - & - \\
5. & $\begin{array}{l}\text { Mix } \\
\text { (campuran) }\end{array}$ & - & - & - & - \\
& $\begin{array}{l}\text { Jumlah } \\
\end{array}$ & 10 & 3 & 13 & 100 \\
\hline
\end{tabular}

Tabel 2. Distribusi frekuensi spesies Plasmodium penyebab malaria di Puskesmas Sungai Durian dan Puskesmas Talawi Kota Sawahlunto selama Bulan Oktober 2011 sampai Februari 2012.

\begin{tabular}{clccc}
\hline No & $\begin{array}{c}\text { Sistem } \\
\text { Plus }\end{array}$ & Jumlah & Keterangan & $\%$ \\
\hline 1. & + & 10 & Infeksi ringan & 100 \\
2. & ++ & 3 & & \\
3. & +++ & - & Infeksi sedang & - \\
4. & ++++ & - & Infeksi berat & - \\
& Jumlah & 13 & & 100 \\
\hline
\end{tabular}

Dari tabel 1. dan tabel 2. terlihat bahwa spesies Plasmodium yang ditemukan adalah Plasmodium falciparum (15,38\%), Plasmodium vivax (76,92\%) dan Plasmodium malariae $(7,69 \%)$. Semua bentuk Plasmodium yang ditemukan dalam penelitian ini adalah stadium tropozoit (stadium cincin).

Tabel 3. Distribusi derajat infeksi dari hasil hitung parasit (parasite count) pada sediaan darah penderita malaria di Puskesmas Sungai Durian dan Puskesmas Talawi Kota Sawahlunto selama Bulan Oktober 2011 sampai Februari 2012.

\begin{tabular}{|c|c|c|c|c|c|}
\hline No. & $\begin{array}{l}\text { Kelompok } \\
\text { Umur }\end{array}$ & $\begin{array}{c}\text { Puskes } \\
\text { mas } \\
\text { Sungai } \\
\text { Durian }\end{array}$ & $\begin{array}{c}\text { Puskesmas } \\
\text { Talawi }\end{array}$ & $\begin{array}{c}\text { Juml } \\
\text { ah }\end{array}$ & $\%$ \\
\hline 1. & $0-11$ bulan & - & - & - & - \\
\hline 2. & $\begin{array}{l}12-23 \\
\text { bulan }\end{array}$ & 1 & - & 1 & 7,69 \\
\hline 3. & $2-4$ tahun & 1 & - & 1 & 7,69 \\
\hline 4. & $5-9$ tahun & 2 & - & 2 & 15,38 \\
\hline 5. & $\begin{array}{l}10-14 \\
\text { tahun }\end{array}$ & 1 & - & 1 & 7,69 \\
\hline \multirow[t]{2}{*}{6.} & $\geq 15$ tahun & 5 & 3 & 8 & 61,54 \\
\hline & Jumlah & 10 & 3 & 13 & 100 \\
\hline
\end{tabular}

Dari tabel 3. terlihat bahwa dari hasil hitung parasit (parasite count) didapatkan semua insiden malaria tergolong derajat infeksi ringan (100\%) dengan parasite count antara 1-100 parasit per 100 lapangan pandang.

Tabel 4. Distribusi insiden malaria berdasarkan umur di Puskesmas Sungai Durian dan Puskesmas Talawi Kota Sawahlunto selama Bulan Oktober 2011 sampai Februari 2012.

\begin{tabular}{|c|c|c|c|c|c|c|c|}
\hline \multirow[t]{2}{*}{$\begin{array}{c}\text { No } \\
\text {. }\end{array}$} & \multirow[t]{2}{*}{$\begin{array}{c}\text { Spesies } \\
\text { Plasmodium }\end{array}$} & \multicolumn{2}{|c|}{$\begin{array}{l}\text { Puskesmas } \\
\text { Sungai } \\
\text { Durian }\end{array}$} & \multicolumn{2}{|c|}{$\begin{array}{c}\text { Puskesmas } \\
\text { Talawi }\end{array}$} & \multicolumn{2}{|c|}{ Jumlah } \\
\hline & & $(+)$ & $(-)$ & $(+)$ & $(-)$ & $(+)$ & $(-)$ \\
\hline 1. & $\begin{array}{l}P . \\
\text { falciparum }\end{array}$ & 1 & & 1 & & 2 & \\
\hline 2. & $P$. vivax & 8 & 225 & 2 & 74 & 10 & 299 \\
\hline 3. & P. malariae & 1 & & - & & 1 & \\
\hline 4. & P. ovale & - & & - & & - & \\
\hline 5. & $\begin{array}{l}\text { Mix } \\
\text { (campuran) } \\
\text { Jumlah }\end{array}$ & $\begin{array}{l}- \\
10\end{array}$ & 225 & - & 74 & $\begin{array}{c}- \\
13\end{array}$ & 299 \\
\hline & Jumlah & diaan & ah ya & diperi & & & \\
\hline
\end{tabular}

Hasil yang diperoleh menunjukkan bahwa insiden malaria tertinggi pada kelompok umur $\geq 15$ tahun, ditemukan penderita sebanyak 8 orang $(61,54 \%)$. 
Tabel 5. Distribusi insiden malaria berdasarkan jenis kelamin di Puskesmas Sungai Durian dan Puskesmas Talawi Kota Sawahlunto selama Bulan Oktober 2011 sampai Februari 2012.

\begin{tabular}{llcccc}
\hline No & $\begin{array}{l}\text { Jenis } \\
\text { Kelamin }\end{array}$ & $\begin{array}{c}\text { Puskesmas } \\
\text { Sungai } \\
\text { Durian }\end{array}$ & $\begin{array}{c}\text { Puskesmas } \\
\text { Talawi }\end{array}$ & $\begin{array}{c}\text { Jum } \\
\text { lah }\end{array}$ & $\%$ \\
\hline 1. & Laki-laki & 6 & 1 & 7 & 53,85 \\
2. & Perempuan & 4 & 2 & 6 & 46,15 \\
& Jumlah & 10 & 3 & 13 & 100 \\
\hline
\end{tabular}

Dari tabel 5. terlihat penduduk laki-laki lebih banyak terinfeksi malaria, yaitu 7 orang $(53,85 \%)$ dibanding penduduk perempuan yang berjumlah 6 orang $(46,15 \%)$.

Jumlah malaria positif dari penelitian ini lebih rendah bila dibandingkan dengan hasil pemeriksaan mikroskopis yang terdapat pada Profil Kesehatan Puskesmas tahun 2010 serta Laporan Kumulatif Penemuan dan Pengobatan Malaria Propinsi Sumatera Barat tahun 2010.,12 Diagnosis malaria ditegakkan dari hasil pemeriksaan laboratorium sediaan darah tepi penderita. ${ }^{13}$ Perbedaan dalam insiden malaria dapat disebabkan oleh faktor waktu pelaksanaan penelitian dan faktor lingkungan, seperti suhu udara, kelembaban, hujan, dan tempat perindukan (breeding place), serta faktor sosial budaya. $^{14}$

Spesies Plasmodium yang dominan adalah Plasmodium vivax $(76,92 \%)$. Spesies yang dominan bisa saja berbeda di lain daerah. Penelitian Irawati (2009) dan Williana (2002) menunjukkan bahwa Plasmodium falciparum (75\%) sebagai spesies paling banyak menyebabkan malaria. ${ }^{15,16} \mathrm{Hal}$ ini sesuai dengan teori bahwa spesies yang banyak dijumpai di Indonesia adalah Plasmodium falciparum dan Plasmodium vivax. ${ }^{17,18}$

Dari hasil penelitian dan pelaporan insiden malaria di Kota Sawahlunto sebelumnya belum pernah teridentifikasi penderita yang terinfeksi parasit Plasmodium malariae. Malaria malariae dapat ditemukan di daerah tropis, tetapi frekuensinya cenderung rendah. Di Indonesia pernah dilaporkan di Papua Barat, Nusa Tenggara Timur (termasuk Timur Leste) dan Sumatera Selatan. ${ }^{19}$ Hal ini mungkin karena banyak penduduk Kota Sawahlunto yang melakukan kunjungan dan berpindah dari Sawahlunto ke Sumatera Selatan atau daerah Indonesia Timur dan sebaliknya.

Dari hasil penelitian tentang penghitungan parasit (parasite count), didapatkan semua sediaan darah positif malaria tergolong infeksi ringan (Tabel 3). Hal tersebut sesuai dengan teori yang menyatakan bahwa infeksi Plasmodium vivax stadium awal (serangan pertama) dan Plasmodium malariae memiliki jumlah parasit yang sedikit dalam peredaran darah tepi. Pada malaria yang disebabkan oleh Plasmodium falciparum, hasil parasite count dapat bervariasi dari infeksi ringan sampai berat. ${ }^{20}$

Berdasarkan kelompok umur tabel 4, terlihat insiden malaria pada dewasa lebih tinggi daripada anak-anak. Penelitian ini juga sesuai dengan hasil Riskesdas (2007) bahwa penderita malaria dominan pada kelompok umur $\geq 15$ tahun. ${ }^{21}$ Hal tersebut diduga karena kegiatan mereka lebih banyak di luar rumah sehingga kemungkinan terserang malaria melalui gigitan nyamuk Anopheles lebih besar. ${ }^{22}$

Bila dilihat dari jenis kelamin pada tabel 5 penduduk yang paling banyak terinfeksi malaria pada penelitian ini adalah laki-laki (53,85\%). Penelitian
Ramadhani (2005) dan Riskesdas (2007) juga menjelaskan bahwa pada malaria ringan jumlah penderita laki-laki lebih banyak. ${ }^{21,23} \mathrm{Hal}$ ini lebih berkaitan dengan aktivitas kerja, sosial dan budaya suatu daerah. ${ }^{14}$ Penduduk laki-laki umumnya sebagai pekerja tambang, petani, sering duduk di luar rumah atau warung pada malam hari dan bahkan mendirikan gubuk di ladang-ladang untuk menjaga hasil pertanian agar tidak diganggu binatang, sehingga berpeluang lebih besar menderita malaria. ${ }^{9} \mathrm{Di}$ negara-negara Timur Tengah yang penduduk wanitanya mengenakan pakaian yang tertutup, frekuensi malaria pada wanita juga lebih rendah jika dibandingkan laki-laki. ${ }^{6}$ Selain itu, penyebab insiden malaria juga dipengaruhi faktor lain yang memungkinkan risiko kontak penderita dengan vektor malaria, seperti tidur tanpa kelambu, tanpa obat nyamuk, atau bangunan rumah yang memberi kesempatan nyamuk vektor malaria masuk pada malam hari. ${ }^{24}$

Tingginya insiden malaria di Kota Sawahlunto beberapa tahun terakhir ini diduga disebabkan oleh berbagai faktor. Keadaan geografis daerah ini yang beragam, yaitu daerah perbukitan, lembah, persawahan, pertambangan, dan dataran yang dilalui sungai-sungai bisa menjadi faktor yang mendukung peningkatan kasus malaria dari tahun ke tahun. Disamping itu, banyaknya hutan dan semak-semak yang baru dibuka untuk pengembangan pariwisata serta lubang-lubang yang terbentuk karena proses pertambangan juga dapat menjadi tempat perindukan (breeding place) vektor malaria.

Penurunan insiden malaria terwujud berkat usaha Dinkes Kota dan Puskesmas beserta jajarannya dalam pengendalian malaria, khususnya pelaksanaan kegiatan penanggulangan penyakit malaria paska KLB pada tahun sebelumnya. Kegiatan-kegiatan yang diselenggarakan adalah penyemprotan dan pengasapan serta penyelidikan epidemiologi dengan melakukan serangkaian kegiatan, meliputi penemuan penderita demam (MFS), pemeriksaan darah seluruh masyarakat, baik yang demam maupun tidak demam (MBS), penyemprotan pada dinding dan loteng bagian dalam rumah (IRS), pengobatan dan follow up minum obat terhadap masyarakat yang positif malaria, serta kegiatan tambahan seperti gotong royong massal dan pembagian kelambu berinsektisida kepada keluarga yang positif malaria di daerah KLB. ${ }^{14,25}$

\section{Kesimpulan}

Insiden malaria di Puskesmas Sungai Durian dan Puskesmas Talawi dominan disebabkan Plasmodium vivax, semua kasus tergolong infeksi ringan, sedangkan distribusi penderita terbanyak pada umur $\geq 15$ tahun dan pada jenis kelamin laki-laki. Penelitian ini menunjukkan penurunan kasus dari tahun sebelumnya.

\section{Daftar Pustaka}

1. WHO. Malaria. (diunduh 21 Mei 2009). Tersedia dari http://www.wpro.who.int/health_topics/malaria/o verview.htm

2. Gunawan, Carta A. Obat antimalaria. Dalam: Harijanto PN, editor. Malaria dari Molekuler ke Klinis. Edisi ke-2. Jakarta. EGC; 2010.

3. WHO. Jurnal malaria WHO: Global report on anti malarial efficacy and drug resistence: 2000-2010. Public Health Promotive and Peventive. 2011. 
4. Astuty, Hendri, Pribadi W. Epidemiologi malaria. Dalam: Parasitologi Kedokteran. Edisi ke-4. Jakarta. FKUI; 2008.

5. Laihad, Ferdinand J. Situasi malaria di Indonesia dan penanggulangannya. Dalam: Harijanto PN, editor. Malaria dari Molekuler ke Klinis. Edisi ke-2. Jakarta. EGC; 2010.

6. Nursuniwati. Insiden malaria di puskesmas Kinali kabupaten Pasaman selama bulan februari 2001 (skripsi). Padang. Fakultas Kedokteran Universitas Andalas. 2001.

7. Dinas Kesehatan Propinsi Sumatera Barat. Laporan kumulatif penemuan dan pengobatan malaria. Padang. 2011

8. Dinas Kesehatan Kota Sawahlunto. Profil Kesehatan Tahun 2010. Sawahlunto. 2011.

9. Badan Pusat Statistik Kota Sawahlunto. Sawahlunto dalam angka (Sawahlunto in figures) 2010. Sawahlunto. 2011

10. Puskesmas Sungai Durian Kota Sawahlunto. Profil kesehatan tahun 2010. Sawahlunto. 2011.

11. Irawati N. Studi keragaman struktur gen MSP plasmodium falciparum di daerah endemi malaria pegunungan dan pantai Sumatera Barat (disertasi). Padang. Fakultas Kedokteran Universitas Andalas. 2009.

12. Dinas Kesehatan Kota Sawahlunto. Laporan bulanan penemuan dan pengobatan malaria kota Sawahlunto tahun 2011. Sawahlunto. 2011.

13. Purwar $Y$, Shah SL, Clarke G, Almugairi $A$ and Muehlenbachs. Automated and supervisid detection of malarial parasites in microscopic images. Malaria Journal. University of Liverpool. 2011.

14. Direktorat PPBB, Dirjen PP dan PL. Menuju eliminasi malaria. Jakarta. Kemenkes RI; 2011.

15. Irawati N. Studi keragaman struktur gen MSP1 plasmodium falciparum di daerah endemi malaria pegunungan dan pantai Sumatera Barat (disertasi). Padang. Fakultas Kedokteran Universitas Andalas. 2009.
16. Williana $H$. Frekuensi malaria di daerah endemis Kenagarian Sungai Pinang kec. Koto XI Tarusan kab. pesisir selatan sumatera barat (skripsi). Fakultas Kedokteran Universitas Andalas. 2002

17. Djamal A. Epidemiologi malaria di Sipora kepulauan Mentawai Sumatera Barat. Laporan Penelitian. Fakultas Kedokteran Universitas Andalas.1990.

18. Sadeli M. Profilaksis alaria. Tinjauan Kepustakaan. Fakultas Kedokteran Universitas Andalas. 1996.

19. Bragonier R, Nasveld P, Auliffe A. Plasmodium malariae in East Timor Southest Asian. J Trop MED Public Health. 2002 ; (33): 689-90.

20. Sutanto I. Parasit malaria. Dalam: Parasitilogi Kedokteran. Edisi ke-4. Jakarta: FKUI; 2008.

21. Badan Penelitian dan Pengembangan Kesehatan. Riskesdas 2007: laporan nasional 2007. Jakarta: Departemen Kesehatan RI; 2008.

22. Harijanto PN. Gejala klinik malaria Ringan. Dalam: Harijanto PN, editor. Malaria dari Molekuler ke Klinis. Edisi ke-2. Jakarta. EGC; 2010.

23. Ramadhani. Status parasitologi dan hematologi malaria serebral dan malaria ringan. (skripsi). Padang. Fakultas Kedokteran Universitas Andalas. 2005

24. Supriyadi, Djaja IM, Adi HK. Faktor yang berhubungan dengan kejadian malaria di kecamatan Kampar Kiri Tengah kabupaten Kampar, 2005/2006. Jakarta. Sistem Informasi Jurnal IImiah UI; 2006.

25. Bidang P2PL. Laporan tahunan seksi pengendalian penyakit (P2) bidang P2 dan PL tahun 2009. Dinas Kesehatan Kota Sawahlunto. 2010. 